\title{
Acometimento intra-ocular na doença de Erdheim- Chester - Primeiro relato na literatura: relato de caso
}

\author{
Intraocular involvement in Erdheim-Chester disease - First report \\ in the literature: case report
}

\author{
Laurentino Biccas Neto \\ Fernando Zanetti ${ }^{2}$
}

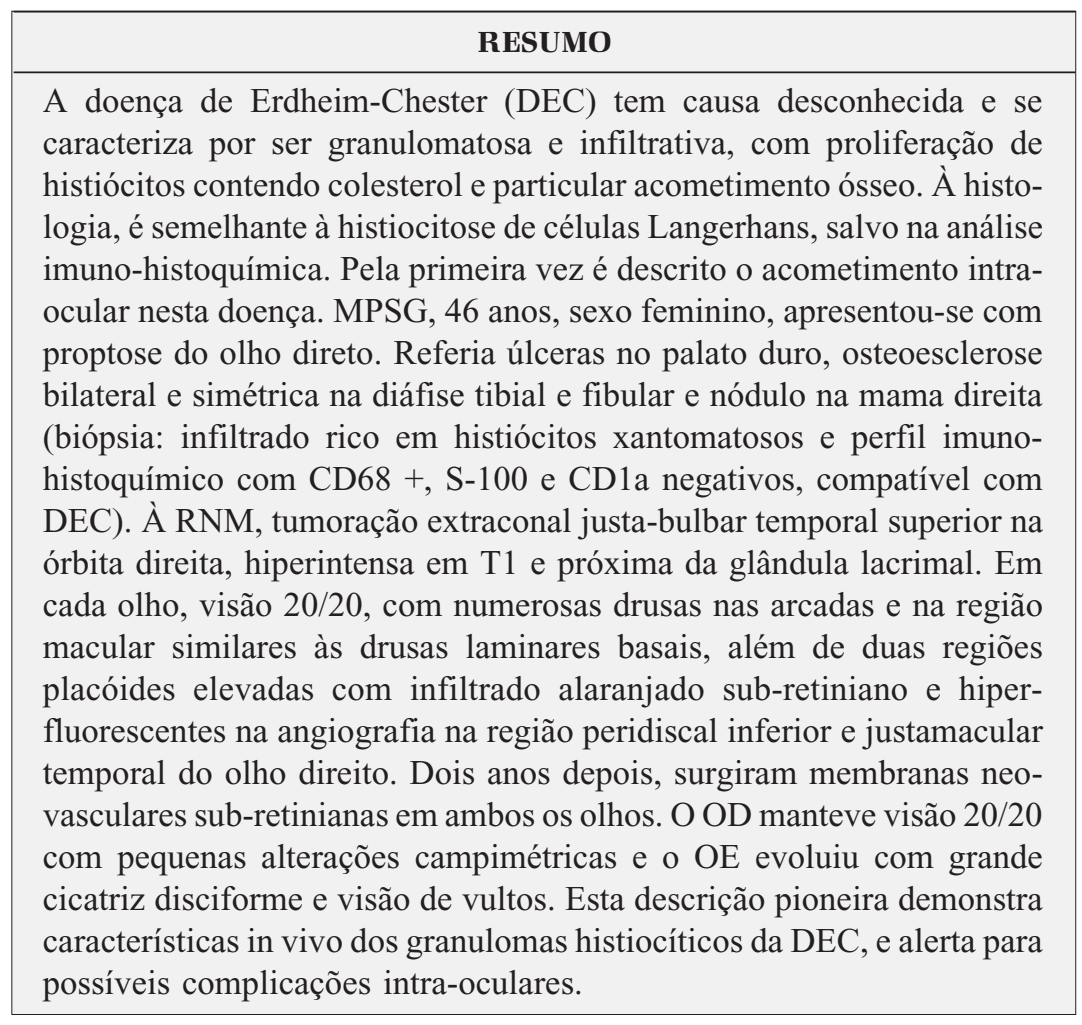

Descritores: Histiocitose; Histiocitose de células não Langerhans; Doença de ErdheimChester; Doenças retinianas; Neovascularização coroidal; Relatos de casos [Tipo de publicação]
Trabalho realizado no setor de Oftalmologia da Escola Superior de Ciências da Santa Casa de Misericórdia de Vitória - EMESCAM - Vitória (ES) - Brasil.

${ }^{1}$ Doutor em Medicina pela Universidade Federal de Minas Gerais - UFMG - Belo Horizonte (MG) - Brasil e Professor Adjunto de Oftalmologia da Escola Superior de Ciências da Santa Casa de Misericórdia de Vitória EMESCAM - Vitória (ES) - Brasil.

${ }^{2}$ Acadêmico da Escola Superior de Ciências da EMESCAM - Vitória (ES) - Brasil.

Endereço para correspondência: Laurentino Biccas Neto. Rua Fortunato Ramos, 411 - Vitória (ES)

CEP 29055-290 - E-mail: biccas@ocular.com.br

Recebido para publicação em 11.02.2007

Última versão recebida em 09.03.2007

Aprovação em 17.03.2007

\section{INTRODUÇÃO}

A doença de Erdheim-Chester (DEC) é uma doença granulomatosa, infiltrativa, de causa desconhecida e caracterizada pela proliferação não neoplásica de histiócitos (macrófagos derivados dos monócitos circulantes e de macrófagos tissulares do sistema retículo endotelial) contendo colesterol, com característico acometimento ósseo ${ }^{(1)}$. À histologia, estes histiócitos mostram-se preenchidos por lipídios, que lhe conferem aspecto amarelado $^{(2-3)}$, em aspecto muito semelhante à histiocitose de células de Langerhans, mas desta diferenciando-se em análise imuno-histoquímica ${ }^{(2)}$.

Desde sua descrição original, em $1930^{(1)}$, não havia sido descrito acometimento ocular ou orbitário na literatura até recentemente, quando dois pacientes com envolvimento orbitário foram relatados ${ }^{(4)}$. 


\section{RELATO DE CASO}

A paciente MPSG, 46 anos, foi referida a um dos autores (LBN) em 2001, sem queixas visuais, por apresentar proptose do olho direito. Ela havia manifestado diabetes melito após prolongada corticoterapia para tratamento de doença granulomatosa sistêmica, que já foi relatada em outra publicação ${ }^{(5)}$. Sucintamente, em 1995 submeteu-se a biópsia de lesões ulceradas no palato duro. $\mathrm{O}$ exame foi compatível com histiocitose de células de Langerhans, demonstrando infiltrado histiocítico (positivo para proteína S100 e CD1a) com eosinófilos dispersos. Foi submetida à radioterapia de feixe externo $(10 \mathrm{x}$ $200 \mathrm{cGy}$ ) com melhora das lesões e o estadiamento radiológico revelou osteoesclerose bilateral e simétrica na diáfise de tíbias e fíbulas. Em 1998, as lesões palatais voltaram, acompanhadas de uma tumoração na mama direita de aproximadamente $3 \mathrm{~cm}$ de diâmetro, com aspectos inespecíficos na mamografia e na ultra-sonografia. Uma biópsia incisional revelou infiltrado rico em histiócitos xantomatosos (Figura 1) que, à imuno-histoquímica, mostrava CD 68+ e S-100 e CDla negativos (achados compatíveis com DEC). A paciente foi então submetida à prolongada corticoterapia até o final de 1999, com regressão das lesões do palato e da mama.

Ao exame oftalmológico em 2001, a acuidade visual corrigida era de 20/20 e a pressão intra-ocular era de $14 \mathrm{mmHg}$, sem alterações biomicroscópicas bilateralmente, exceto pela presença de exuberantes xantelasmas palpebrais. As versões oculares eram normais e havia discreta proptose do olho direito (18 $\mathrm{mm}$ contra $16 \mathrm{~mm}$ no olho direito e no olho esquerdo método de Hertel). Uma ressonância nuclear magnética contrastada revelou tumoração extraconal temporal superior no setor temporal superior do olho esquerdo, hiperintensa em T1 e próxima da glândula lacrimal.

À fundoscopia (Figura 2) numerosas drusas nas arcadas e

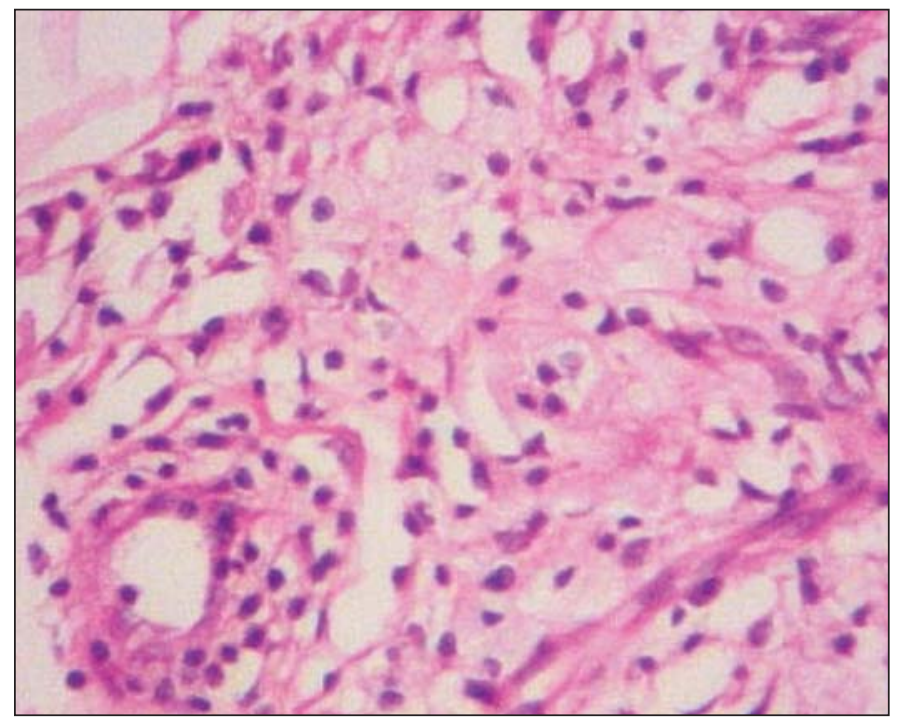

Figura 1 - Biópsia de mama demonstrando infiltrado de histiócitos com citoplasma esponjoso e núcleos picnóticos - hematoxilina e eosina, 1000x na região macular de cada olho similares às drusas laminares basais, progressivamente hiperfluorescentes no angiograma (Figura 3). No olho direito, duas regiões placóides elevadas mostrando infiltrado amarelado sub-retiniano com hiperfluorescência progressiva na angiofluoresceinografia: uma justafoveal temporal ( $<1$ diâmetro de disco óptico) e outra maior, circundiscal inferiormente (hiperreflexiva e causando leve sombreamento na ultra-sonografia B).

A paciente só retornou para acompanhamento dois anos depois - esteve sob tratamento em outro Estado (quimioterapia sistêmica e dois transplantes medulares sucessivos) - relatando baixa da acuidade visual profunda no olho esquerdo. Ao exame, acuidade visual corrigida de $20 / 20$ e de percepção de vultos (1/200) no olho direito e no olho esquerdo, respectivamente. Notava-se regressão plena do infiltrado justamacular temporal no olho direito, que, entretanto, exibia crescimento da lesão justadiscal inferior associada a importante hemorragia circundiscal. O sangramento sugeria presença de membrana neovascular sub-retiniana que não era visível à angiografia (Figura 4). O olho esquerdo exibia cicatriz fibrovascular subfoveal associada a alguma hemorragia sub-retiniana, sugestiva de estágio cicatricial de membrana neovascular sub-macular (Figura 4). Uma tomografia de coerência óptica (Figura 5) confirmou a suspeita de complicações neovasculares bilaterais: no olho direito observou-se lesão compatível com membrana neovascular coroideana adjacente ao infiltrado subretiniano com fluido associado (vazamento ativo) na região peridiscal, além de descolamento seroso neurorretiniano secundário na região justafoveal nasal. O olho esquerdo já exibia cicatriz fibrovascular central, com atrofia macular.

Foi colocada para a paciente a possibilidade de tratar-se o olho esquerdo com terapia fotodinâmica para evitar-se perda visual adicional, mas a mesma preferiu, em face da pouca perspectiva de resultados e do alto custo do procedimento, contemporizá-la. A mesma conduta foi adotada no olho direito, já que a membrana neovascular sub-retiniana peridiscal em jovens pode ter comportamento benigno ${ }^{(6)}$ e o prejuízo visual era mínimo.

A paciente foi acompanhada a curtos intervalos, sem piora do quadro em cada olho. Um ano depois, houve regressão completa e espontânea da membrana neovascular sub-retiniana peridiscal no olho direito, que manteve o infiltrado fucsinóide justadiscal inferiormente e acuidade visual corrigida de 20/20 (Figura 6). O campo visual deste olho é preservado, embora haja importante aumento da mancha cega e escotoma arqueado superior incompleto, na correspondência retinotópica da infiltração justadiscal (Figura 7). No olho esquerdo, houve aumento da membrana neovascular sub-macular, que progrediu na direção temporal inferior (Figura 6). Estes aspectos mantiveram-se até sua última consulta em fevereiro de 2007.

\section{COMENTÁRIOS}

A região orbitária pode ser acometida por várias doenças infiltrativas causadas por proliferações histiocíticas, como a 

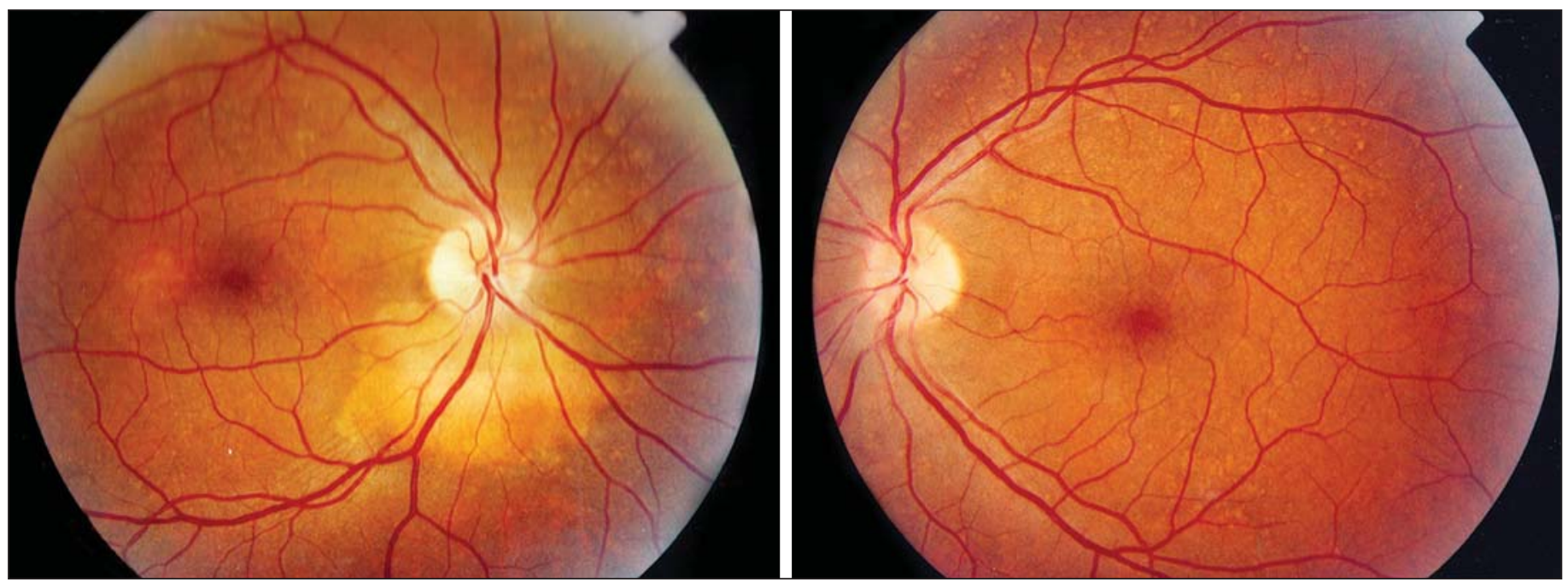

Figura 2 - Aspecto fundoscópico na primeira consulta
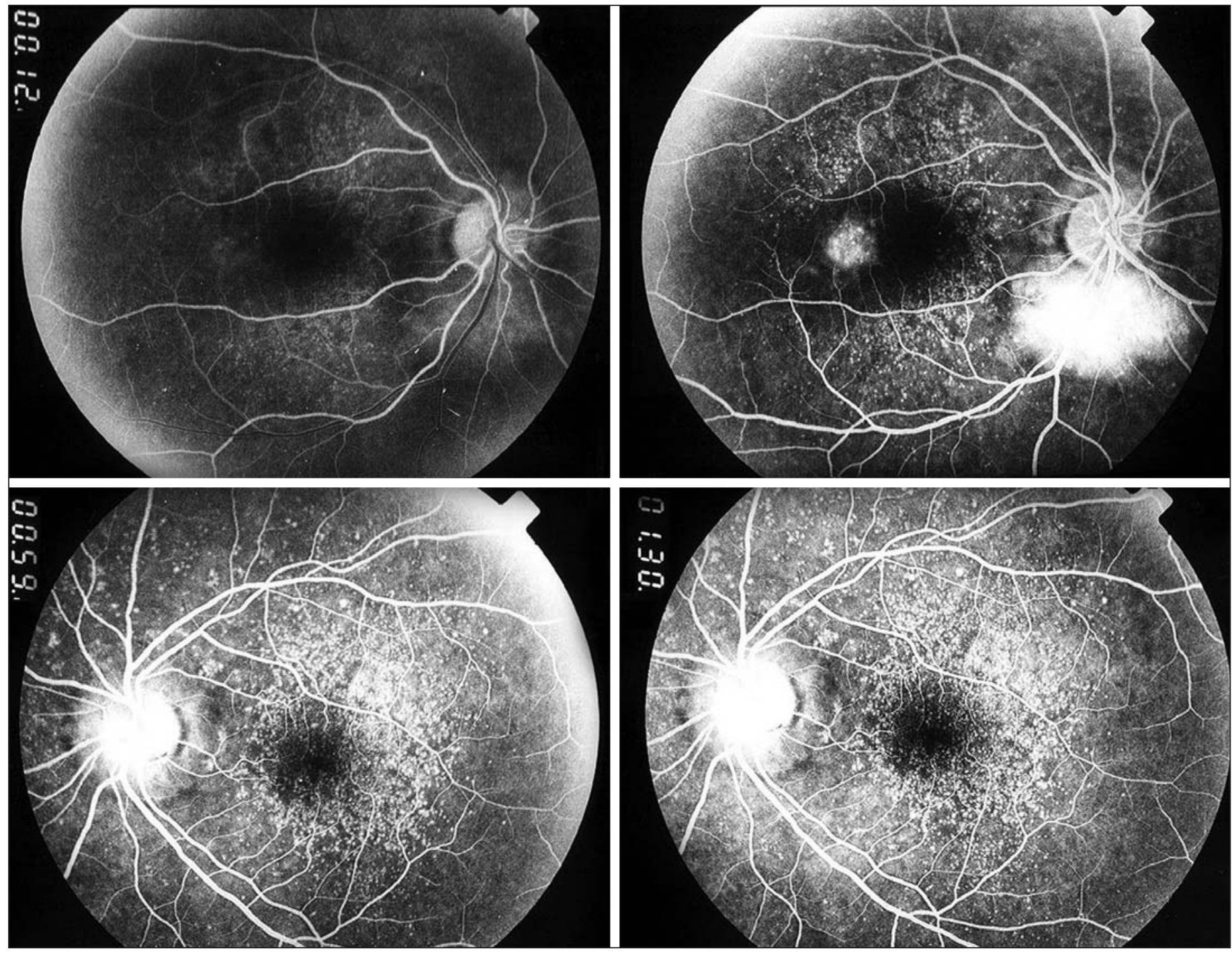

Figura 3 - Angiofluoresceinografia à primeira consulta: fases de enchimento à esquerda e de trânsito à direita no olho direito (acima) e no olho esquerdo (abaixo) 

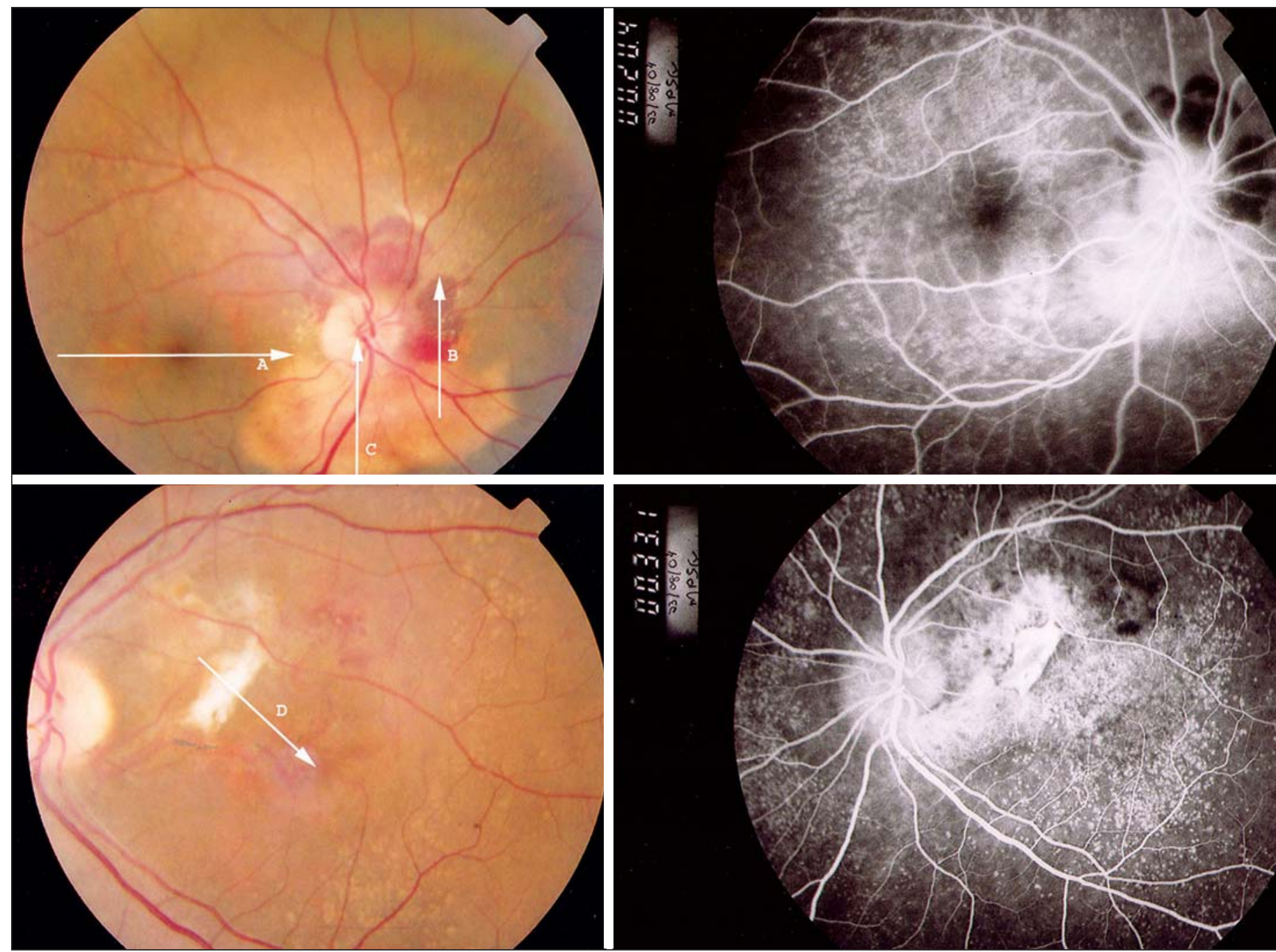

Figura 4 - Membrana neovascular sub-retiniana bilateral - ativa no olho direito em torno do disco óptico e cicatricial sob a mácula do olho esquerdo

histiocitose $\mathrm{X}$, o xantogranuloma juvenil, a doença de Erdheim-Chester e o xantogranuloma necrobiótico. Estas doenças caracterizam-se pela proliferação não neoplásica de histiócitos, habitualmente acometendo a pele e podendo ter complicações sistêmicas graves ${ }^{(7)}$.

$\mathrm{O}$ acometimento intra-ocular, por sua vez, é extremamente raro. Pode haver infiltração uveal na histiocitose $\mathrm{X}$ disseminada ${ }^{(8-9)}$, embora esta complicação não tenha sido observada em grandes séries históricas de crianças afetadas ${ }^{(10)}$. No xantogranuloma juvenil, pode ocorrer em 0,5 a $1,0 \%$ dos pacientes com acometimento dermatológico ${ }^{(11)}$, principalmente em crianças com menos de 1 ano de idade e com lesões irianas, embora órbitas, nervo óptico, retina e coróide também possam ser acometidas ${ }^{(12-13)}$. O acometimento intra-ocular é extremamente raro em adultos, encontrando-se relatos de lesões irianas, mas não no segmento posterior ${ }^{(12)}$.

Lesões infiltrativas sub-retinianas de aspecto amarelado foram observadas nesta paciente, o que pode significar a presença no local de típico infiltrado histiocítico e de conteú- do lipídico. Na histiocitose X foi descrita "gliose retiniana" e turvação vítrea intensa por cristais lipídicos. À histopatologia observaram-se granulomas retinianos com células gigantes e células de Touton, além de células xantomatosas no vítreo. Não foram vistos sinais inflamatórios ${ }^{(9)}$.

O surgimento de neovascularização coroideana nos locais afetados pode representar uma evolução da história natural da doença. No xantogranuloma infantil, hifema é o principal sintoma associado às lesões irianas, mostrando que as lesões infiltrativas do trato uveal podem sangrar e erodir-se ao longo de sua evolução ${ }^{(14)}$. Não se pode correlacionar o achado de depósitos drusenóides aos aspectos infiltrativos típicos da doença à primeira vista, mas seu registro é importante para observação em futuros portadores desta rara moléstia. Optouse neste caso pela não realização de biópsia das lesões intraoculares em face dos estudos histopatológicos e imuno-histoquímicos inequívocos das lesões extra-oculares examinadas, evitando-se, assim, os riscos desta abordagem.

Por fim, este relato pioneiro de manifestações intra-ocula- 

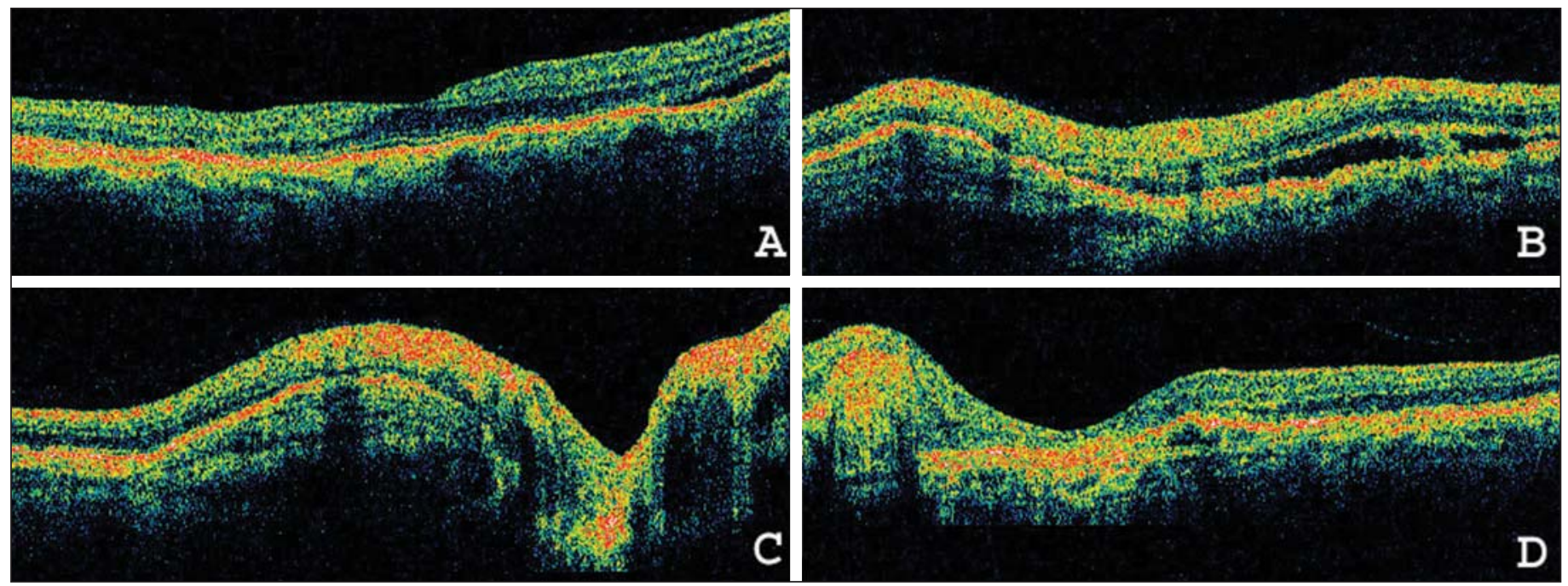

Figura 5 - Imagens à tomografia de coerência óptica de cortes correspondentes às setas aplicadas na figura 4, A: demonstrando fluido sub-macular no setor temporal no olho direito, conseqüente à atividade da membrana neovascular sub-retiniana peridiscal (que não acomete o território macular central); B: na região justadiscal nasal deste olho observa-se inferiormente o depósito de material alaranjado sub-retiniano elevando a neurorretina, com densidade média e homogênea, associado superiormente a descolamento seroso da neurorretina com alterações no fuso epitélio pigmentado retiniano-coriocapilar sugestivos de membrana neovascular sub-retiniana que invade o espaço sobre este epitélio; C: corte vertical longitudinal englobando o nervo óptico superiormente, demonstrando novamente o infiltrado extenso sub-retiniano inferiormente; D: corte radial mostrando atrofia macular holo-retiniana no olho esquerdo associada superiormente à lesão fibrovascular cicatricial sub-retiniana, visível como elevação exuberante de alta refletividade solidária ao fuso epitélio pigmentado retiniano-coriocapilar, sem fluido associado

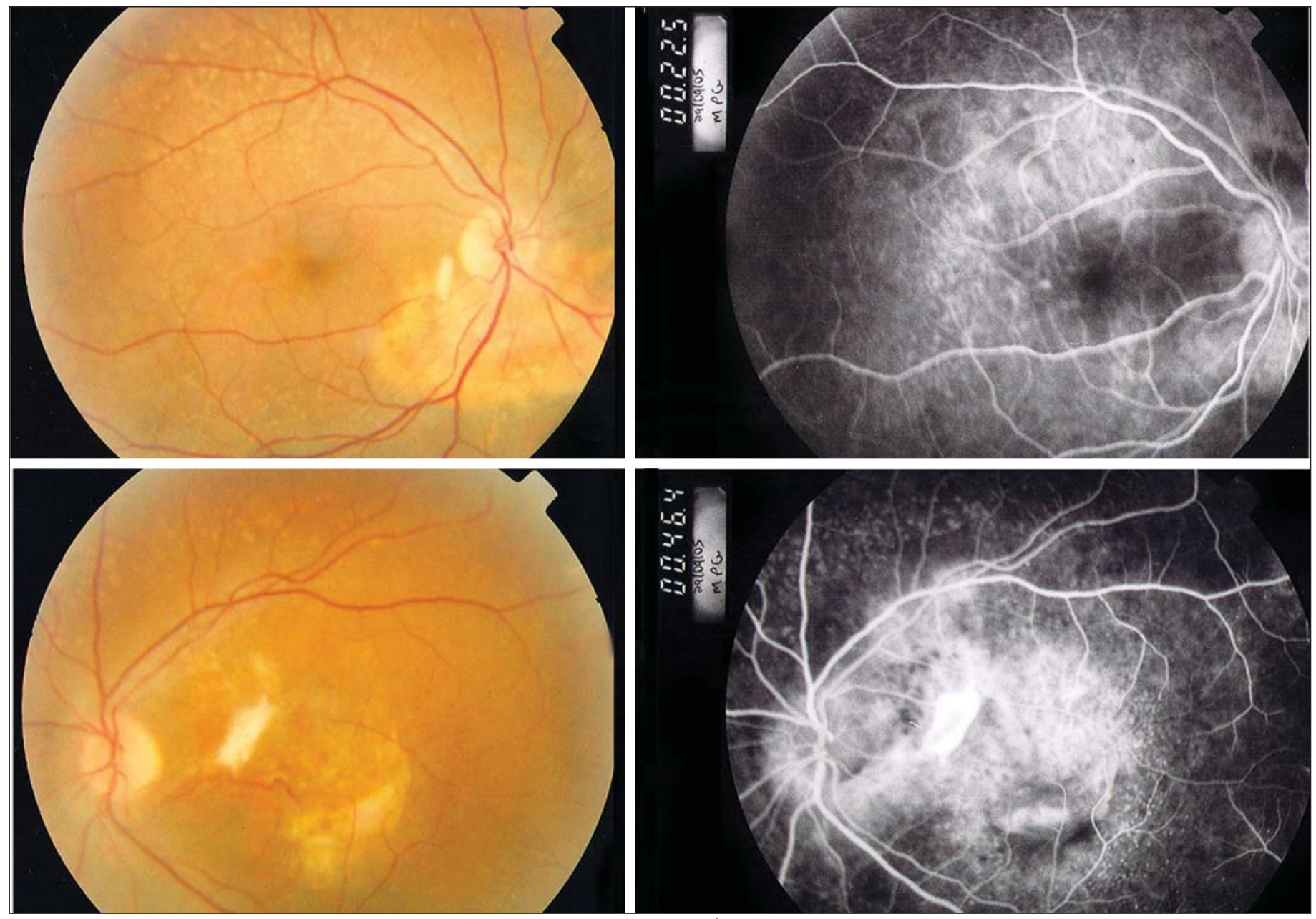

Figura 6 - Retinografia colorida e fluorescente mostrando a regressão espontânea da membrana neovascular sub-retiniana no olho direito e da cicatriz fibrovascular residual no olho esquerdo 


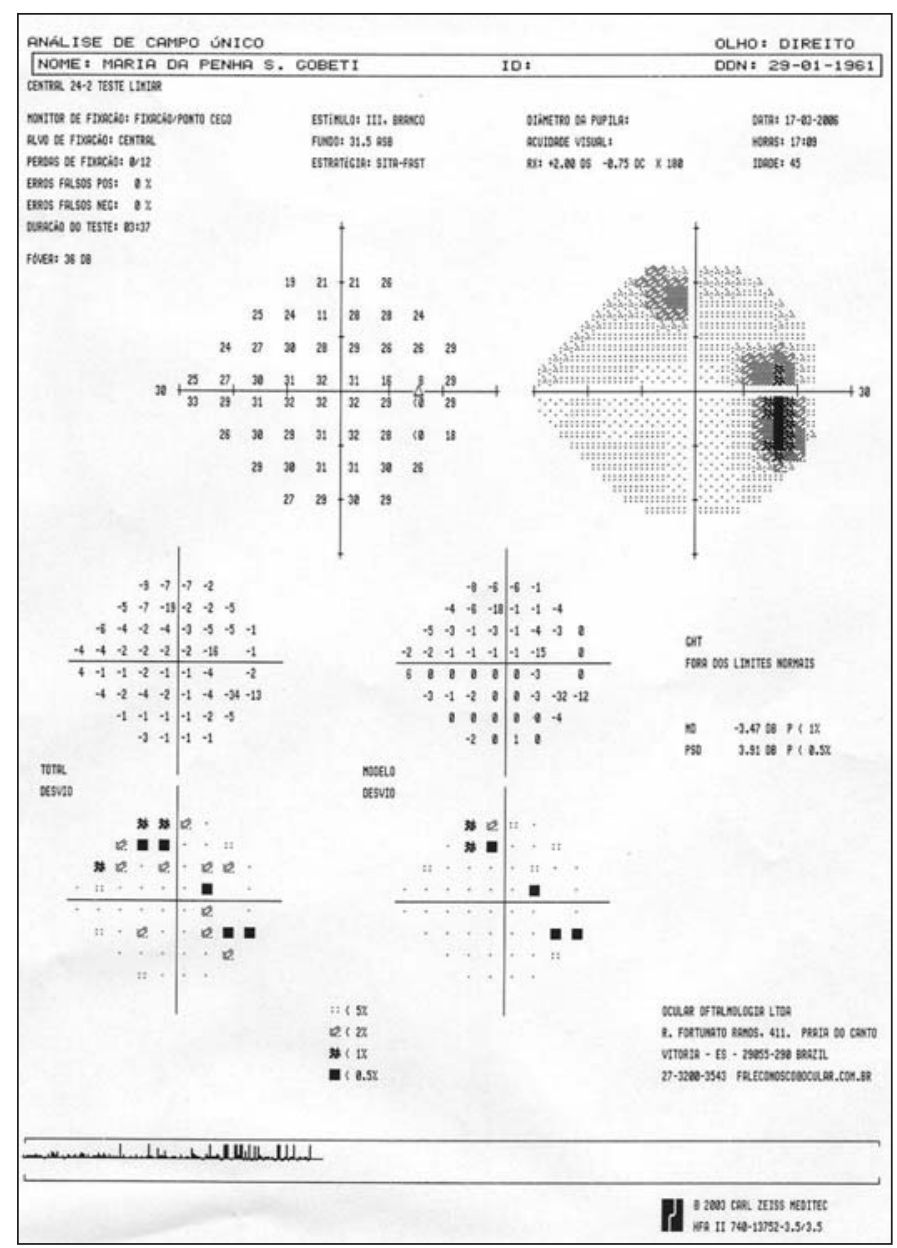

Figura 7 - Campimetria visual computadorizada do olho direito, demonstrando aumento da mancha cega na projeção retinotópica do infiltrado peridiscal, associado a pequeno escotoma de média intensidade e isolado superior

res da doença de Erdheim-Chester confirmada à histopatologia alerta para possíveis complicações no acometimento do segmento posterior ocular que podem resultar em graves seqüelas visuais.

\section{ABSTRACT}

Erdheim-Chester disease (ECD) is a granulomatous and infiltrative disorder of unknown etiology with proliferation of cholesterol-containing histiocytes and peculiar bone involvement. It is very similar to Langerhans cell histiocytosis (LCH) on histology but with a different immunohistochemical profile. This is the first report of intraocular involvement in this disease. MPSG, a 46 y.o. woman, presented with proptosis of the OD. She referred ulcerated lesions on the hard palate, symmetrical and bilateral osteosclerosis of the fibulae and tibiae and a nodule in the right breast (biopsy: xantomatous histiocytic infiltrate CD68+, S-100 and CD1a negative on immunohistochemistry compatible with ECD). MRI studies demonstrated an extraconal tumor in the juxtabulbar temporal portion of the right orbit close to the lacrimal gland and hyperintense on T1. Vision was 20/20 OU, with numerous drusen in the posterior pole, similar to basal laminar drusen. Two regions of orange subretinal infiltrates that showed progressive staining on the angiogram were seen in the peripapillary region and also close to the fovea in the OD. Choroidal neovascular membranes were seen 2 years later in OU leading to severe visual loss in the OS and to a slight visual field loss in the OD, which retained 20/20 vision. This pioneer report depicts in vivo characteristics of histiocytic granulomas in ECD. Caution should be taken with patients with ECD as potentially blinding intraocular complications may arise.

Keywords: Histiocytosis; Histiocytosis, non-Langerhanscell; Erdheim-Chester disease; Retinal diseases; Choroidal neovascularization; Case reports [Publication type]

\section{REFERÊNCIAS}

1. Chester W. Über Lipoidgranulomatose. Virchows Arch Pathol Anat. 1930; 279:561-602.

2. Kenn W, Eck M, Allolio B, Jakob F, Illg A, Marx A, et al. Erdheim-Chester disease: evidence for a disease entity different from Langerhans cell histiocytosis? Three cases with detailed radiological and immunohistochemical analysis. Hum Pathol. 2000;31(6):734-9.

3. Kinosian HJ. Systemic histiocytosis with intraocular involvement: report of a case. Am J Ophthalmol. 1960;49:987-93.

4. Alper MG, Zimmerman LE, Piana FG. Orbital manifestations of ErdheimChester disease. Trans Am Ophthalmol Soc. 1983;81:64-85.

5. Andrade VP, Nemer CC, Prezotti AN, Goulart WS. Erdheim-Chester disease of the breast associated with Langerhans-cell histiocytosis of the hard palate. Virchows Arch. 2004;445(4):405-9.

6. Silvestri G, Archer DB, Johnston PB. Peripapillary subretinal neovascular membranes: the natural history. Eye. 1993;7(Pt 3):398-402.

7. Schellini SA, Sampaio Júnior AA, Marques MEA, Corpa MVN. Xantogranuloma órbito-palpebral: relato de caso. Arq Bras Oftalmol. 2004;67(3):549-52.

8. Blank H, Eglick PG, Beerman H. Nevoxanthoendothelioma with ocular involvement. Pediatrics. 1949;4:349-54.

9. Mozziconacci P, Offret G, Forest A, Attal C, Girard F, Hayem F, Pham Huu Trung. [Histiocytosis-X with ocular lesions. Anatomical study]. Ann Pediatr (Paris). 1966;13(5):348-55. French.

10. Moore AT, Pritchard J, Taylor DS. Histiocytosis X: an ophthalmological review. Br J Ophthalmol. 1985;69(1):7-14.

11. Chang MW, Frieden IJ, Good W. The risk intraocular juvenile xanthogranuloma: survey of current practices and assessment of risk. J Am Acad Dermatol. 1996;34(3):445-9.

12. Parmley VC, George DP, Fannin LA. Juvenile xanthogranuloma of the iris in an adult. Arch Ophthalmol. 1998;116(3):377-9. Review.

13. Shields JA, Eagle RC Jr, Shields CL, Collins ML, DePotter P. Iris juvenile xanthogranuloma studied by immunohistochemistry and flow cytometry. Ophthalmic Surg Lasers. 1997;28(2):140-4.

14. Karcioglu ZA, Mullaney PB. Diagnosis and management of iris juvenile xanthogranuloma. J Pediatr Ophthalmol Strabismus. 1997;34(1):44-51. 